This is the accepted version of Dolan, Catherine S. Ryus, Caitlin R., Dopson, Sue, Montgomary Paul, Scott, Linda. 'A Blind Spot in Girls' Education: Menarche and its Webs of Exclusion in Ghana' Journal of International Development 26 (5), 643-657. Published online by Taylor and Francis on 29 April 2013, available at:

http://onlinelibrary. wiley.com/doi/10.1002/iid.2917/abstract;jsessionid=C3A1FC45938B5F2FB06C2207EC4A69C5.f0 $\underline{2 \mathrm{t} 01}$

Accepted Version downloaded from SOAS Research Online: http://eprints.soas.ac.uk/19420/

A Blind Spot in Girls' Education: Menarche and its Webs of Exclusion in Ghana

Keywords: education, development, gender, puberty, menarche 


\section{A Blind Spot in Girls' Education: Menarche and its Webs of Exclusion in Ghana}

\section{Introduction}

Educating girls has widespread benefits, from improved health and reduced population growth to increased productivity and economic growth. Over the last decade, this awareness has moved girls' education to the forefront of national policy and international agreements and today achieving gender parity in educational enrolment is, against what once seemed unfathomable odds, within reach for many developing countries (UNESCO, 2010). However, despite notable progress in girls' educational achievement (Lloyd and Young, 2009), differences in educational opportunities for boys and girls persist (Herz and Sperling, 2004). One of the most obvious yet frequently overlooked of these differences is the process of maturation itself, including menstruation.

Research suggests that the onset of puberty disproportionately affects girls' educational prospects, particularly in developing countries where concerns about girls' safety and modesty, pressures for early marriage, and economic imperatives are often barriers to their schooling. ${ }^{1}$ Recently, however, media (BBC, January 2010; Kristoff, 2010) and NGO accounts (FAWE, 2004; Ten, 2007) have claimed that it is not simply puberty but inadequate sanitary care that poses an obstacle to the education of post-pubescent girls, a claim that has galvanized a range of actors-from celebrity activists and multinational corporations to social enterprises and government ministries — to raise menstrual management as a development concern, with several initiatives emerging to increase access to sanitary pads, fund the provision of private changing areas and sanitary facilities, and

\footnotetext{
${ }^{1}$ See Mehrah (1995), Sommer (2009), Kristoff and Dunn (2009) and Mahon and Fernandes
} (2010). 
improve access to water at school. Yet despite the growing number of initiatives focused on the issue, the relationship between sanitary care and girls' education remains largely unsubstantiated. To date, there has been little academic attention awarded to the issue and no empirical evidence demonstrating that such measures actually improve educational outcomes.

This paper, based on a pilot study in Ghana, offers such evidence. The study assessed the impact of sanitary pads and puberty education on the school attendance of post-pubertal girls, as well as the implications of menarche for their well-being. The findings suggest that provisions for menstrual sanitary care (e.g., privacy for changing, access to water, and hygienic materials to manage menstruation) and exposure to puberty education has a positive effect on girls' school attendance and subjective well-being, and may provide a fruitful tool in strategies that aim to improve girls' educational outcomes.

The paper is structured as follows. Section 1 provides an overview of the intersection between gender, education, and puberty, and sketches out how menstruation shapes the educational experience of girls. Section 2 describes the study's methodology, which aimed to gain a qualitative understanding of the socio-cultural and material implications of menstruation and statistical evidence of the relationship between menstrual management and school attendance through a non-randomised control trial (hereafter the 'intervention'). Section 3 explores how menarche dovetails with educational attainment in material ways - through the provision of hygiene facilities, the withholding of family economic support, scarcity of private space, pressure for early marriage, and so on. Section 4 presents the results of the intervention, showing the relationship between the provision of sanitary pads and school attendance.

\section{The Puberty and Education Nexus}


Eliminating educational disparities is widely recognised as an effective way to enhance women's bargaining power and contribute to a range of positive development outcomes (World Bank, 2001). Countries investing in girls' education typically enjoy higher economic growth and reduced poverty (Abu Ghaida and Klasen, 2004), as well as several positive public health outcomes including lower HIV transmission rates, lower infant and maternal mortality, better child nutrition, fewer early pregnancies, and decreased fertility rates (see Lloyd and Young, 2009 and Herz and Sperling, 2004 for reviews). These outcomes are more pronounced when the impact of secondary schooling is measured (Murphy and Carr, 2007).

Such economic and health dividends have prompted considerable investment in girls' education, with propitious results. Across the world the gender parity index (GPI) (the ratio of boys to girls enrolled in school) has markedly improved, particularly at the primary level (UNESCO, 2010). Measures that equate enrolment with educational improvement, however, present an incomplete picture of the experiences of girls and often obscure the effects of stronger contributors to the long-term societal benefits of education. For instance, levels of school enrolment are often far greater than those of attendance, particularly in contexts of poverty where fluctuations in attendance are often the norm. In sub-Saharan Africa (SSA) daily attendance rates in secondary school often fall below $70 \%$ and in some cases even lower (e.g., at harvest time) (Ampiah, 2008; Lewin, 2009). Nor do enrolment-based measurements indicate anything about educational attainment or quality — key determinants of education's social and health returns; in Ghana, for example, over $50 \%$ women and $33 \%$ of men aged 15 to 29 who had completed six years of school could not read a sentence (EFA 2012).

Interpreting progress from enrolment data may also mask other inequalities (e.g., socioeconomic status and geographical variation) that create differential educational 
outcomes (Kane, 2004; Lewin, 2009). In Ghana, for instance, more than half to two-thirds of all females in the Northern, Upper East, and Upper West regions have never been to school, compared with less than one-fifth in the Greater Accra and Ashanti regions (GSS et al., 2009).

This geographical disadvantage is crosscut by economic marginalisation, typically the most powerful determinant of access to and retention in school (UNESCO, 2010), and even in Ghana, where formal primary school fees have been abolished, the costs of uniforms, transport, books and supplies still pose formidable barriers to school entry and completion for poor children. Poverty, in particular, disproportionately reduces the likelihood of girls' schooling as the opportunity costs of girls' education (e.g., loss of their domestic and productive labour) increases the perceived costs of educating girls (Kane, 2004). In Ghana, for example, $62 \%$ of females in the poorest quintile have no formal education in contrast to $10 \%$ in the wealthiest quintile (GSS et al., 2009), and poor girls are more likely to drop out than other children (Lewin, 2009).

The privileging of enrolment data also sidelines discussion of how cultural, material, and biological processes shape girls' educational prospects. Whereas anthropologists have long documented the norms, practices and processes of exclusion associated with menstruation (Douglas, 1966; Buckley and Gottlieb, 1998), and other social scientists have demonstrated how nutrition (Bundy et al. 2009), health (Clark et al., 2008), school uniforms and fees (Evans et al., 2008), and infrastructural constraints (Coclough et al., 2000) affect attendance and learning outcomes, the connection between sanitary care and education has gone largely unrecognised in education and development studies. A literature search of the top 17 international development journals, as determined by impact factor, for 1995-2011 found that only four of 13,000 articles in the sample addressed the connection between menstruation, facilities at school, limited access to sanitary products, 
and absenteeism. ${ }^{2}$ Only one, Mahon and Fernandes (2010), mentioned the lack of sanitary products as a potential barrier to education.

Recently, however, several international agencies and NGOs (e.g. Population Council, Plan International, CARE, Oxfam and Unicef) have suggested that infrastructural constraints such as a lack of private latrines, water, and sanitary supplies may exacerbate the difficulties associated with girls' schooling (Kirk and Sommer, 2006; Ten, 2007) and several initiatives in Africa have tackled some of these constraints, making menstrual products more widely available (e.g., Living Goods in Uganda; Governments of Kenya [Gathigah 2011] and India [Gargh et al. 2012]; Procter and Gamble; UNICEF), affordable (e.g. FAWE in Uganda and Binti Africa in Kenya), and eco-friendly (e.g. Huru in Kenya and Sustainable Health Enterprises in Rwanda). While these schemes vary in terms of products (from reusable cloth pads to disposable pads made from banana fiber) and business models (from donation campaigns to micro-finance loans), they all assume that access to sanitary pads will increase school attendance and improve educational outcomes. This conviction, however, is based on two previously unsubstantiated assumptions. First, menstruation, rather than say the nature of school facilities, teacher quality and so on, causes girls to miss school, an assumption that has gained currency through the circulation of several 'authoritative' reports (e.g. Unicef, 2011; World Bank, 2005; GAPS/FAWE Uganda). Unicef (2011), for example, asserts that 10\% of school age girls in Africa do not attend school during their periods while the World Bank (2005) concluded that a girl could miss between $10-20 \%$ of the school year. The methods of these reports, however, are often unexplained, and few are grounded in empirical observation. Second, providing sanitary pads will improve school attendance. However, empirical research to support this assertion

\footnotetext{
${ }^{2}$ These are: Mahon and Fernandes (2010), Ivens (2008), Glick (2008) and Kirk (2004).
} 
is lacking; to date there has only been one other study, conducted by Oster and Thornton (2010), to test the relationship between sanitary care and educational outcomes. Their study, based on the provision of menstrual cups in suburban Nepal, found little improvement in the attendance rates of adolescent girls. However, not only was attendance already fairly high $(86 \%)$ at baseline, suggesting a ceiling effect, but girls in the study enjoyed conditions (water, private bathrooms) the majority of African girls do not experience; only one of the over 20 schools we visited during our study, from remote rural schools to middle class schools in urban Accra, had a girls-only private space for changing and only two had water nearby.

As a whole then, the evidence on the relationship between menstruation and education has been largely anecdotal and/or non generalisable. It does, however, point to the need to understand the circumstances and conditions associated with menstruation, and the extent to which it shapes the educational, public health and economic prospects of girls and their communities.

\section{Research Methods}

The government of Ghana has demonstrated a strong commitment to girls' education, and is on target for reaching universal primary education (EFA 2012). However, despite notable progress at primary school levels, there has been a decline in completion rates for girls at the junior high school level and an increased gap in the GPI from primary to senior high school (Camfed Ghana, 2011). In 2008-2009 we conducted a two stage qualitative and quantitative study to investigate whether and how puberty, and menstruation in particular, might contribute to gender asymmetry in attendance in late primary and junior secondary education. 
Stage One of the study, conducted in 2008, consisted of qualitative research in Accra, as well as the Western, Central, Upper East, and Ashante regions to accommodate for regional variations in cultural norms, geographic constraints, religion, and economic opportunities. To acquire a broad understanding of attitudes and practices surrounding girls' education, puberty and reproductive health, we first conducted focus group discussions (FGDs) with a range of stakeholders (parents, teachers, government officials and civil society organisations). These discussions provided the basis for subsequent focus group discussions and semi-structured interviews conducted with adolescent schoolgirls and drop-outs (see Table 1 for summary of qualitative research). Given the sensitive and private nature of the subject matter, young women working with our partner NGO interviewed girls. All interviews and focus groups were audio taped and subsequently transcribed into English.

Insert Table 1

Building on the learnings derived from the qualitative research, we initiated Stage Two: a five-month non-randomized trial that examined the impact the provision of sanitary pads and/or puberty education on girls' school attendance. The intervention was conducted in four sites --- three peri-urban sites in Central region (Awutu-Effutu-Senya and Effutu Municipal Districts) and one rural site in the Ashanti region (Sekyere West District). Each of the four sites had a primary and junior secondary school, and we studied all schoolgirls aged 12 and older, irrespective of menstrual status $(n=120)$. Sites were chosen to ensure ethnic, economic, and cultural ${ }^{3}$ generalizability and to capture how

\footnotetext{
${ }^{3}$ Results from Stage 1 had indicated that religious affiliation was not a key determinant in
} 
differences in economic development (presence of retail, employment opportunities, poverty indices etc.) and infrastructure (roads, telecommunications, and availability of sanitary facilities at school etc.) influenced girls' educational prospects and experiences of puberty, including menstruation. The rural Ashanti site, for example, was selected specifically because of its remoteness; our initial focus groups indicated that the location had no electricity, water, or paved roads, and no previous experience with sanitary pads. By contrast, in the peri-urban areas, disposable sanitary pads were available from shops within walking distance from school, and some girls in focus group discussions reported using pads occasionally. We expected to see differential results between the peri-urban and rural pads sites. Because sanitary pads were a new technology in the latter, any improvements in attendance, participation in daily activities, and self-esteem could be attributed to pads. Conversely, we predicted a diminished effect from pads in the peri-urban village due to the availability of sanitary pads and suspected any improvements in attendance, daily activities, and self-esteem to speak to the girls' lack of access to sanitary provisions rather than to novelty.

The intervention consisted of three different treatments: two pads-with-puberty education $(\mathrm{Pads}+\mathrm{Ed})$ villages and one puberty education-only (Ed only) village, ${ }^{4}$ which

the nature of menstrual management.

\footnotetext{
${ }^{4}$ Puberty education was based on the curriculum used by the Ghana Education Service and material contained in the UNICEF 'Gender and Relationships' Programme (see:

http://www.unicef.org/lifeskills/index_14927.html.).
} 
we compared to one control village (see Table 2). ${ }^{5}$ In each treatment village (those receiving pads and/or puberty education), we administered four surveys: a baseline assessment, two interim questionnaires, and a final assessment. In the control site, we collected data only at the completion of the study. ${ }^{6}$ The following sections describe our findings, focusing firstly on the learning derived from the qualitative research on how the cultural and biological process of menstruation shapes the educational prospects and experience of girls, and secondly presenting the results of the intervention on whether the provision of sanitary pads and/or puberty education improve school attendance.

Insert Table 2

\section{The Context of Menarche}

Our qualitative research paints a picture of menarche as a fraught process, characterised by uncertainty, fear, and distress. In contrast to the experience of many young girls in Europe and North America, most girls in our study had little or no knowledge of menstruation or the biological processes of maturation prior to the onset of menarche. They claimed that their families rarely discussed puberty and reproductive concerns with them, as social norms inhibited communication about and disclosure of menstrual status. As a woman in

\footnotetext{
${ }^{5} \mathrm{~A}$ pads-only site was not included because we considered it ethically problematic to introduce sanitary pads without education where many girls had no personal experience with them.

${ }^{6}$ We compared official attendance data with actual student attendance at every site visit and found acceptable levels of agreement indicating strong reliability of the school attendance data.
} 
one of our rural focus group discussions said, "[t]here is a culture in Ghana that you and your daughter should not be too close ... You will be criticised for discussing such issues with your daughter as it would be seen as publicly disclosing private issues" (10/10/2008). Girls whose families informed them about menstruation prior to menarche reported being told little other than to notify a female in their family (usually a mother, aunt, or grandmother). As one 16-year-old girl described, "I had no knowledge about menstruation and when I first saw it, I thought it was sickness. I was very shy and kept it to myself. My mother got to know about it later and was annoyed because she says according to our culture if I cook while menstruating I will die. She taught me to use cloth but warned me not to be telling people about my menses and to be wary of boys" (Interview, 9/10/2008). As a result, girls' understanding of menstruation was freighted with misconceptions; it connoted fear of their body, of boys, and of participating in what were once 'typical' activities (e.g., cooking, praying, fetching water, or serving guests). Rather than elevated to 'sacred' status, menstruation was embedded in 'a culture of concealment' (Houppert, 2000), manifested in taboos, euphemisms, and secrecy that not only left girls embarrassed, but ashamed, isolated and insecure.

According to girls, this veil of silence not only contributed to their sense of shame and exclusion, but also left them with little practical understanding of how to manage their menses. Despite being a 'natural' process, menstruation was not easily understood or accommodated by 'traditional' strategies of menstrual management. Indeed, the research found that an attachment to 'traditional' methods (e.g., cloth) often served as a foil for embedded gender inequalities. For example, while parents deemed traditional methods as adequate, girls told us that cloth and tissue were unreliable means of protection when walking the long distances to school. In the rural site, where cloth is the only available means of menstrual protection and girls had to walk approximately one hour and twenty 
minutes to reach school, over three quarters of girls reported soiling garments during their previous period, an occurrence with emotional as well as educational consequences as most girls own only one school uniform and lack the resources to obtain another. As a 15-yearold respondent in the rural site described, "I am scared of soiling my dress because I am using the cloth and have to be very conscious about that. I have soiled myself once at school and I went home but never returned" (Interview, 9/10/2008). The possibility of soiling or giving off a scent when wearing cloth not only made attending school a risky proposition but also rendered concentration while there extremely difficult. Girls discussed their fear of being 'found out' in class and the anxiety of starting their period during school where there was no water and/or private areas in which change. Though it is the policy of the Ministry of Education that schools keep sanitary pads on site for emergencies, no schools we visited had such provisions.

The constraints associated with menstruation were particularly pronounced in the rural site as the use of cloth inhibited a wide range of activities from playing, doing household chores or engaging with boys (see Table 3). But girls in all sites described the need to conceal menstruation, often drying used cloth in hiding places, such as under beds, where they remained damp. Because cloth is scarce, many girls wore a damp, dirty cloth all day, and also reported sharing cloths with other women in their household. This may have contribuetd to the skin irritations and pelvic infections girls experienced on a regular basis, an issue that may not only affect their school attendance and performance but their reproductive health (e.g., fertility) (Adinma and Adinma, 2008).

Insert Table 3

Even in peri-urban treatment sites, where disposable pads are typically available at local shops, few parents provided them. Some girls would save their pocket money to 
purchase them while others would engage in transactional sex for sanitary pads, as well as books, uniforms and other necessities. As one girl explained, "I use some of the money given to me by my boyfriend to purchase the pads and for personal upkeep. I use the cloth when I don't have money for pads. I will sacrifice to buy pads" (Interview, 8/10/2008). Yet while such alliances may facilitate access to sanitary pads, they may also portend the end of a girls' educational future, leading to pregnancy, early marriage and school drop-out. As one girl who dropped out in junior secondary school described, "I have a nine month old baby ... I befriended a boy age 20 . He provided me with some finances. He later got me pregnant and I am now married to him. I had no previous knowledge on menstruation before menstruating. I didn't menstruate before getting pregnant so I haven't menstruated before" (Interview 7/10/2008).

Finally, the lack of adequate sanitary protection often magnifies a number of adverse events precipitated by menarche. Menarche was a transitional moment for girls in our study — their world became smaller as they confronted a new set of gender expectations and the prevailing norms surrounding female sexuality. We found that, as a signal of reproductive capacity and hence adulthood, menarche triggered an array of negative practices that together diminished the likelihood a girl would stay in school. This included what girls described as "eve teasing", harassment and abuse (physical, sexual and verbal) from teachers as well as fellow students, withdrawal of economic support from the home, and pressure from family to marry, take a boyfriend or leave the community to find work in the markets of Kumasi or as a domestic servant in Accra. ${ }^{7}$ As a result, many girls were reluctant to disclose their menstrual status, aware of the risks its visibility entailed.

\footnotetext{
${ }^{7}$ See Mahon and Fernandes (2010), Kirk and Sommer (2006), and GAPS \& FAWE Uganda (1999) for similar findings in other contexts.
} 
However, in a context where cultural taboos effectively broadcast a girls' menstrual status and where the use of cloth leaves them vulnerable to conspicuous soiling, maintaining informational privacy is extremely difficult.

The onset of menarche also appeared to compromise, if not at jeopardise girls' educational futures (see also: Chowdhury and Trovato, 1994; Mahon and Fernandes, 2010). This became clear during focus group discussions with teachers, who described a precipitous drop in girls' enrolment between primary 6 and junior secondary school, a phenomenon that was substantiated by Stage 2 quantitative work, which showed that enrolment parity dropped dramatically (below .4$)^{8}$ by the end of junior secondary school (see Figure 1, which depicts the relationship between gender parity and the percent of girls in each grade who reached menarche).

Thus, a picture emerges of menarche as much more than a 'natural' biological process; rather it marks a physiological transition that can dramatically redefine the opportunities of girls, and in particular their educational futures. Whether the adverse effects of this transition can be moderated by the provision of sanitary care was the focus of the intervention, to which we now turn.

\section{Insert Figure 1}

\section{Stage Two: The Intervention}

The goal of the intervention was to determine whether the provision of sanitary pads and puberty education would potentially mitigate some of the negative events associated with

\footnotetext{
${ }^{8}$ Using the enrolment data from all the schools in the intervention segment of the study, gender parity indices were calculated for each grade level from primary form 4 to junior secondary form $3(n=488)$.
} 
menarche by improving girls' attendance and retention at school. As described previously, to do so we instituted an intervention with three arms of treatment (see Table 2). While attendance $^{9}$ did not vary between groups at baseline (pre-intervention), over the five-month period of the intervention, attendance rose in the Pads + Ed groups by $9 \%$ (i.e., approximately six days per term out of a possible 65 days, or 18 out of 196 days per year). The control group showed no significant difference in attendance between baseline and follow-up (see Table 4).

\section{Insert Table 4}

Importantly, attendance effects were consistent across pad sites despite significant differences in socioeconomic status (see Figure 2). The longer walking distance, lack of toilet facilities, ubiquitous cloth usage, and markedly lower material wealth in the rural site did not result in a more pronounced attendance effect from pads. Conversely, despite higher wealth, better latrines, accessibility of pads, and short distances between home and school, the periurban site similarly responded to the provision of pads. This suggests that the effect of pads may be less sensitive to socioeconomic context than often assumed, and that sanitary pads may be as inaccessible to wealthier girls in peri-urban villages where pads are readily available as to girls in rural areas where they are not. In other words, despite claims that sanitary pads are too expensive for poor households (e.g., Kanyike et al., 2004), cost may not be the over-riding issue, but rather a girl's menstrual needs must compete against the needs and spending preferences of her family, a family in which she has little power to shape how income is used and distributed. This suggests that the degree to which menstruation acts as a barrier to education may be as, if not more, related to socio-cultural norms, including the intrahousehold allocation patterns that are widely recognised to

\footnotetext{
${ }_{9}^{9}$ Attendance was measured as a percent of school days attended per term.
} 
disadvantage women in parts of sub-Saharan Africa (Whitehead and Kabeer, 2001), than to household wealth or geographical constraints.

\section{Insert Figure 2.}

Figure 2 shows that, although attendance rates were initially unchanged in the educationonly group, by follow-up this group achieved a similar high mean attendance rate as the pads-with-education sites. A longer-term trial is needed to confirm this effect, however it may be that education is the "active ingredient" in the intervention and that providing girls with information, resources, and support may enable them to better navigate the school environment. We note, however, that education alone did not reduce their feelings of shame and insecurity. All three subjective measures—shame, self-confidence, and insecurity—had significantly stronger responses in sites that received pads (see Table 5). For example, at baseline, $90.5 \%$ of the girls in the rural site and $54.2 \%$ in all three periurban sites reported experiencing shame during their periods (no significant difference noted between peri-urban sites). Following the intervention, $66 \%$ and $86 \%$ of girls in the rural and peri urban Pads + Ed sites respectively reported feeling less ashamed in contrast to $44.9 \%$ of girls in the Ed Only site. Girls in the rural and peri-urban Pads + Ed sites were twice and seven times as likely respectively as those in the Ed Only site to report a decrease in feelings of shame. Similarly, at baseline, close to three-quarters of girls in the rural Pads + Ed site (73.7\%) and two-thirds (64.1\%) in the peri-urban Pads + Ed site reported feeling less self-confident during their periods. Although these girls were still more likely to report feeling less-self confident than girls in the education-only site, significant improvement in self-confidence was demonstrated only among girls who received pads $(\mathrm{p}<.001)$. Similarly, reports of feeling insecure during one's period significantly decreased only in sites with pads between baseline and follow-up $(\mathrm{p}<.001)$. 


\section{Insert Table 5}

Finally, the data suggest improvements in subjective well-being are associated with an increased capacity to engage in the classroom. During our interviews, girls reported feeling distracted in school because of the inadequacy of the methods for managing their menses and were, in particular, afraid to stand and respond to teachers' questions for fear of exposing the backs of their dresses. It was only at treatment sites with pads that girls' ability to concentrate at school improved between baseline and follow-up $(p<.001)$; of girls who received pads, $98.4 \%$ reported that they were better able to perform in school (see Table 5), suggesting that the provision of sanitary care may mitigate menstruation-related anxiety and potentially enhance girls' receptivity to classroom instruction.

\section{Concluding Observations}

Over the last decade, as the correlation between girls' education and key public health and economic measures has become clear, governments, donors and the private sector have turned their attention to menstruation as a potential barrier to the educational achievement of adolescent girls. Yet despite the growing number of initiatives focused on sanitary care, there has been no data to indicate that menarche, or the process of menstrual management, has an actual impact on school attendance, retention and/or completion. This paper has presented data from a two stage pilot study conducted in Ghana, which qualitatively examined the effects of menarche for the experiences and opportunities of girls and conducted a non randomised control trial on the potential benefit of sanitary pads with reproductive education for girls' schooling. The qualitative research highlights the way menarche acts as a tipping point in the life course of girls (Cavanagh et al., 2007), catalysing an array of negative events with significant ramifications for their social participation, 
education, and health, and by extension their long-term economic opportunities. The intervention, the first study to assess the efficacy of sanitary pads with education for school attendance among menstruating students in Africa, demonstrated that the provision of sanitary pads and puberty education improved the school attendance of post-pubescent girl students by around $9 \%$ and reduced feelings of shame, insecurity, low self-confidence and poor concentration. The intervention also showed that the benefits of reliable sanitary care and puberty education were present in both rural and peri-urban sites, indicating that neither geography (distance to school), infrastructural (access to water) and/or socioeconomic (poverty) factors mitigate the positive effects of sanitary care.

Taken together the qualitative and quantitative data demonstrate that understanding the role adequate sanitary care plays in constraining or facilitating girls' access to education is certainly a legitimate area of development concern. Importantly, the study also provides donors, national governments and development organisations much-needed evidence to support existing and/or forthcoming hygiene and sanitation interventions, which to date have been largely grounded in untested assumptions. But while the findings make clear the relationship between menstruation and educational attainment, they also raise questions on the viability of current sanitary pad initiatives. Menstrual management does not operate in a vacuum; it is implicated by situated cultural processes, including gender and generational power structures. For example, while cloth is unreliable, older generations expressed little need to meddle with this longstanding, 'traditional' method of menstrual management, and in so doing enforced rather than challenged the shame and fear that surrounded menstruation. Similarly, even in cases where families could access and afford sanitary pads, they were deemed an unnecessary 'luxury', suggesting that it is not simply cost or awareness but gender-based allocation priorities that will determine girls' access to sanitary care. At the same time, while manufactured sanitary pads may improve girls' participation in family, 
school and social life, they also pose cultural and environmental challenges. Our study found that girls buried their used pads in the forest because they feared their pads would be seen by others or retrieved for purposes of witchcraft. Any device that required a girl to deposit a used pad in an open container and/or public setting thus would be avoided, suggesting that the environmentally preferable disposal method --- incinerators --- need to take girls' need for privacy into account. In such situations, disposable sanitary pads may be less feasible and/or environmentally sustainable than hygienic reusable cloth.

Advancing policy for the provision of sanitary care, therefore, will need to move beyond simply providing a technology like sanitary pads to considering how menstruation interweaves with the wider social-cultural context of fertility, marriage and reproduction to shape the opportunities of young girls. Indeed, while sanitary pads may improve girls' educational prospects, they will not, alone, tackle the multiple challenges—gender discrimination, socio-cultural norms, inequitable educational culture and poor school infrastructure- that continue to face girls' education.

\section{Acknowledgements}

We would like to thank the editor of the journal and two anonymous referees for their valuable comments on the paper. We would also like to thank Templeton College, the John Fell Fund and Green Templeton College - all at Oxford University for their support of this research. Special thanks also go to Jim Hecimovich, CARE International, FURDEV of Ghana, Plan International, the Ghanaian Ministries of Education and Health, as well as the participating girls and schools. 


\section{References}

Abu-Ghaida, D, Klasen, S. 2004. The costs of missing the millennium development goal on gender equity. World Development 32 (7): 1075-1107.

Adinma, E, Adinma, J. 2008. Perceptions and practices on menstruation amongst Nigerian secondary school girls. African Reproductive Health 12 (1): 74-83.

Ampiah, J. 2008. An investigation of provision of quality basic education in Ghana: A case study of selected schools in the Central Region. Journal of International Cooperation 11 (3): 1937.

BBC. 2010. Sanitary pads help Ghana girls go to school. BBC News, January 29, 2010. http://news.bbc.co.uk/1/hi/8488375.stm

Buckley, T, Gottlieb, A. 1988. Blood Magic: The Anthropology of Menstruation. University of California Press, Berkeley.

Bundy, D. 2009. Rethinking school feeding: social safety nets, child development, and the education sector. World Bank, Washington, DC.

Camfed Ghana. 2011. What works in girls' education in Ghana: A critical review of the Ghanaian and international literature, https://camfed.org/media/uploads/files/What_Works_in_Girls_Education_in_Ghana__A_Critical_Review_Precis.pdf

Cavanagh, S, Riegle-Crumb, C, Crosnoe, R. 2007. Puberty and the education of girls. Social Psychology Quarterly 70 (2): 186-198.

Chowdhury, F, Trovato, F. 1994. The role and status of women and the timing of marriage in five Asian countries. Journal of Comparative Family Studies 25 (2): 143-157.

Clark, SE, Jukes, M, Njagi, J, Khasakhala, L, Cundill B, Otido J, Crudder C, Estambale B, Brooker, S. 2008. Effect of intermittent preventive treatment of malaria on health and education in schoolchildren, Lancet 372 (9633): 127-138.

Coclough, C, Rose, P, Tembon, M. 2000. Gender inequalities in primary schooling: the roles of poverty and adverse cultural practice. International Journal of Educational Development 20 (1): 5-27.

Douglas, M. 1966. Purity and Danger. Routledge and Kegan Paul, London.

Evans, D, Kremer, M, Ngatia, M. 2008. The Impact of Distributing School Uniforms on Children's Education in Kenya. World Bank, Washington. 
EFA. 2012. EFA Global Monitoring Report. NY: UNESCO Publishing.

FAWE Uganda. 2004. Sexual maturation in relation to education of girls in Uganda: documenting good practices in girls' education. Unpublished report. FAWE Uganda, Kampala.

Gathigah. M. 2011. Kenya: government funds free sanitary pads for schoolgirls, The Guardian, http://www.guardian.co.uk/global-development/2011/jul/29/kenya-schoolgirlssanitary-pads-funding.

Garg, R., Goyal, S., Gupta, S. 2012. India moves towards menstrual hygiene: subsidized sanitary napkins for rural adolescent girls_-issues and challenges. Maternal and Child Health Journal 16 (4): 767-774.

GAPS \& FAWE Uganda. 1999. Gender and Primary School. Kampala: FAWE Uganda.

Ghana Statistical Service (GSS), Ghana Health Service (GHS), and ICF Macro. 2009. Ghana Demographic and Health Survey 2008. Accra, Ghana: GSS, GHS, and ICF Macro.

Glick, P. 2008. What policies will reduce gender schooling gaps in developing countries: evidence and interpretation. World Development 36 (9): 1623-1646.

Herz, B, Sperling, G. 2004. What works in girls' education: evidence and policies from the developing world. Council on Foreign Relations, NY.

Houppert, K. 2000. The Curse: Confronting the Last Unmentionable Taboo: Menstruation. Farrar, Straus and Giroux, New York.

Ivens, S. 2008. Does increased water access empower women? Development 51: 63-67.

Kane, E. 2004. Girls' education in Africa: What do we know about strategies that work? Africa Region Human Development Working Paper Series. World Bank, Washington, DC.

Kanyike, F, Akankwasa, D, Karungi, C. 2004. Menstruation as a barrier to gender equality in Uganda, Insights Education \#3, IDS, Brighton.

Kirk, J. 2004. Promoting a gender justice peace, Gender and Development 12(3): 50-59.

Kirk, J, Sommer, M. 2006. Menstruation and body awareness: linking girls' health with girls' education, http://www.schools.watsan.net/content/download/323/2726/, accessed 16 September 2010.

Kristof, N, WuDunn, S. 2009. Half the Sky: Turning Oppression into Opportunity for Women Worldwide. Knopf, New York. 
Kristof, N. 2010. A strategy for keeping African girls in School. NY Times, February 27, 2010.

Lewin, K. 2009. Access to education in sub-Saharan Africa: patterns, problems and possibilities. Comparative Education 45 (2): 151-174.

Lloyd, CB, Young, J. 2009. New Lessons: The Power of Educating Adolescent Girls. Population Council, NY.

Mahon, T, Fernandes, M. 2010. Menstrual hygiene in South Asia: a neglected issue for WASH (water, sanitation and hygiene) programmes. Gender and Development 18 (1): 99-113.

Mehrah, G. 1995. Girls' drop-out from primary schooling in the Middle East and North Africa: Challenges and Alternatives. United Nations Children's Fund, Amman, Jordan.

Ministry of Education. 2012. Ghana National Education Assessment 2011 Findings Report, Accra: Ministry of Education, Ghana Education Service, Assessment Services Unit.

Murphy, E, Carr, D. 2007. Powerful partners adolescent girls: education and delayed childbearing. Population Reference Bureau, Washington DC.

Oster, E, Thornton, R. 2010. Menstruation, sanitary products and school attendance: evidence from a randomized evaluation. Working paper. Northwestern University, Evanston, IL.

Sommer, M. 2009. Ideologies of sexuality, menstruation and risk: girls' experiences of puberty and schooling in northern Tanzania. Culture, Health \& Sexuality 11 (4) 383-398.

Ten, VTA. 2007. Menstrual hygiene: a neglected condition for the achievement of several millennium development goals. Europe External Policy Advisors, Zoetermeer, the Netherlands.

UNESCO. 2010. Global education digest 2010: comparing education statistics across the world, UNESCO Institute for Statistics, Montreal, CA.

Unicef. 2011. Menstruation and hygiene: critical issues for girl's education in Tanzania, http://www.twesa.org/documents/Menstruation\%20-\%20UNICEF\%20proposal.pdf

World Bank. 2001. Engendering development. The World Bank, Washington, DC.

World Bank. 2005. Toolkit on hygiene sanitation and\& water in schools: gender roles and impact, http://www.wsp.org/wsp/Hygiene-Sanitation-WaterToolkit/BasicPrinciples/GenderRoles.html, accessed 17 September 2010. 
Table 1: Summary of qualitative research with schoolgirls, parents and educators

\begin{tabular}{|c|c|c|c|c|c|c|}
\hline \multicolumn{3}{|c|}{ Semi-Structured Interviews: Schoolgirls } & \multicolumn{4}{|c|}{ Focus Group Discussions (FGDs): Schoolgirls \& Drop-outs } \\
\hline Date & Place & \# Interviewed & Date & Place & \# FGDs & \# Participants \\
\hline $02 / 10-8 / 10 / 08$ & Accra & 32 & $02 / 10 / 08$ & Accra & 1 & 10 \\
\hline 09/10/08 & Adidwan & 10 & $22 / 09-07 / 10 / 08$ & Aframano & 2 & 19 \\
\hline $14 / 10 / 08$ & Akraman & 6 & $10 / 10 / 08$ & Amansie West & 1 & 12 \\
\hline $10 / 10 / 08$ & Amansie & 6 & 08/10/08 & Beposo & 2 & 20 \\
\hline 08/10/08 & Beposo & 11 & $27 / 01 / 09$ & NR Bolga & 1 & 43 \\
\hline $14 / 10 / 08$ & Mankessim & 15 & $25 / 09-13 / 10 / 08$ & Mankessim & 3 & 32 \\
\hline $28 / 10 / 08$ & NR Bolga & 10 & \multicolumn{2}{|l|}{ Total } & 10 & 136 \\
\hline $27 / 10 / 08$ & Nyorgbawe & 9 & \multicolumn{4}{|c|}{ Focus Group Discussions (FGDs): Parents } \\
\hline Total & & 99 & Date & Place & \# FGDs & \# Participants \\
\hline \multicolumn{3}{|c|}{ Interviews/Meetings: Educators } & 09/10/08 & Adidwan & 2 & 50 \\
\hline Date & Place & \# Participants & $07 / 10 / 08$ & Aframano & 1 & 20 \\
\hline $17 / 09-2 / 10 / 08$ & Accra & 3 & $22 / 09-8 / 10 / 08$ & Beposo & 3 & 52 \\
\hline $07 / 10 / 08-22 / 1 / 09$ & Aframano & 3 & $13 / 10 / 08$ & Mankessim & 1 & 19 \\
\hline $14 / 10 / 08$ & Akraman & 2 & $28 / 01 / 09$ & NR Bolga & 1 & 30 \\
\hline $22 / 09-8 / 10 / 08$ & Beposo & 2 & $27 / 01 / 09$ & Nyorgbawe & 1 & 75 \\
\hline $27 / 01 / 09$ & Bolgatanga & 7 & \multicolumn{2}{|l|}{ Total } & 9 & 246 \\
\hline $30 / 01 / 09$ & Chochoe & 2 & \multicolumn{4}{|c|}{ Focus Group Discussions (FGDs): Educators } \\
\hline $24 / 09-13 / 10 / 08$ & Mankessim & 4 & Date & Place & \# FGDs & \# Participants \\
\hline $27 / 01 / 09$ & Northern & 2 & 09/10/08 & Adidwan & 2 & 9 \\
\hline $30 / 01 / 09$ & Winneba & 3 & $25 / 09 / 08$ & Akraman & 1 & 6 \\
\hline \multirow{2}{*}{\multicolumn{2}{|c|}{ Total }} & 28 & $23 / 01 / 09$ & Brofoyedu & 1 & 5 \\
\hline & & & $25 / 9 / 08$ & Mankessim & 1 & 105 \\
\hline & & & $23 / 01 / 09$ & Nsuase & 1 & 6 \\
\hline & & & $28 / 01 / 09$ & NR Bolga & 1 & 5 \\
\hline & & & $27 / 01 / 09$ & Nyorgbawe & 1 & 8 \\
\hline & & & \multicolumn{2}{|l|}{ Total } & 8 & 144 \\
\hline
\end{tabular}


Table 2: Sites, interventions, timing and materials

\begin{tabular}{|c|c|c|c|}
\hline Treatment & Location & Material & $\begin{array}{l}\text { Timing of } \\
\text { survey } \\
\text { assessments }\end{array}$ \\
\hline $\begin{array}{l}\text { Pads-with- } \\
\text { Education } \\
(n=39)\end{array}$ & Periurban & $\begin{array}{l}\text { sanitary pads, } \\
\text { underwear, } \\
\text { calendar, pencil, } \\
\text { sharpener }\end{array}$ & $\begin{array}{l}\text { Months 1, 3, 4, \& } \\
5\end{array}$ \\
\hline $\begin{array}{l}\text { Pads-with- } \\
\text { Education } \\
(\mathrm{n}=21)\end{array}$ & Rural & $\begin{array}{l}\text { sanitary pads, } \\
\text { underwear, } \\
\text { calendar, pencil, } \\
\text { sharpener }\end{array}$ & $\begin{array}{l}\text { Months 1, 3, 4, \& } \\
5\end{array}$ \\
\hline $\begin{array}{l}\text { Education only } \\
(n=25)\end{array}$ & Periurban & $\begin{array}{l}\text { calendar, pencil, } \\
\text { sharpener }\end{array}$ & $\begin{array}{l}\text { Months 1, 3, 4, \& } \\
5\end{array}$ \\
\hline $\begin{array}{l}\text { None (Control) } \\
(n=35)\end{array}$ & Periurban & nothing & Month 5 \\
\hline
\end{tabular}

Table 3. Menstruation and participation in daily activities

\begin{tabular}{lcc}
\hline Does menstruation ever cause you to... & $\begin{array}{l}\text { Rural Village } \\
\text { (\% Yes) }\end{array}$ & $\begin{array}{c}\text { Periurban } \\
\text { Villages } \\
\text { (\% Yes) }\end{array}$ \\
\hline Miss school? & 95.2 & 20.2 \\
Be unable to play with other children? & 85.7 & 33.3 \\
Miss work? & 66.7 & 29.3 \\
Avoid physical activities? & 61.9 & 38.4 \\
Remain indoors? & 57.1 & 22.2 \\
Avoid being around boys or men? & 57.1 & 35.4 \\
Be unable to carry out daily activities? & 52.4 & 29.3 \\
\hline
\end{tabular}


Table 4. Percent of school days attended across sites over time

\begin{tabular}{lllll}
\hline Treatment & Location & $\begin{array}{c}\text { Baseline } \\
\text { (mean, SD) }\end{array}$ & $\begin{array}{c}\text { Midpoint } \\
\text { (mean, SD) }\end{array}$ & $\begin{array}{c}\text { Follow-up } \\
\text { (mean, SD) }\end{array}$ \\
\hline $\begin{array}{l}\text { Pads-with- } \\
\text { Education }\end{array}$ & Periurban & $82.27(28.05)$ & $90.58(11.20)$ & $90.93(19.21)$ \\
$\begin{array}{l}\text { Pads-with- } \\
\text { Education }\end{array}$ & Rural & $80.68(14.73)$ & $91.91(5.41)$ & $91.09(9.06)$ \\
$\begin{array}{l}\text { Education only } \\
\text { Control }\end{array}$ & Periurban & $78.03(26.25)$ & $78.96(19.70)$ & $91.36(8.31)$ \\
\hline $\mathrm{n}=120$ & Periurban & $88.43(13.44)$ & $82.14(13.62)$ & $83.21(13.91)$ \\
\hline
\end{tabular}

Table 5. Subjective measures: pre and post intervention

\begin{tabular}{|c|c|c|c|c|c|c|c|c|}
\hline \multirow[t]{2}{*}{$\begin{array}{l}\text { Percent of girls } \\
\text { who experience }\end{array}$} & \multicolumn{2}{|c|}{ Shame } & \multicolumn{2}{|c|}{$\begin{array}{l}\text { Lack of Self- } \\
\text { Confidence }\end{array}$} & \multicolumn{2}{|c|}{ Insecurity } & \multicolumn{2}{|c|}{$\begin{array}{c}\text { Difficulty } \\
\text { Concentrating }\end{array}$} \\
\hline & Baseline & Follow-up & Baseline & Follow-up & Baseline & Follow-up & Baseline & Follow-up \\
\hline $\begin{array}{l}\text { Rural } \\
\text { Pads+Education }\end{array}$ & 90.5 & 65.7 & 73.7 & $33.3^{* *}$ & 47.6 & $18.6^{* *}$ & 77.8 & $58.3^{* *}$ \\
\hline $\begin{array}{l}\text { Periurban } \\
\text { Pads+Education }\end{array}$ & 59.0 & 86.0 & 64.1 & $22.5^{* *}$ & 17.9 & $5.6 * *$ & 61.5 & $37.5^{* *}$ \\
\hline $\begin{array}{l}\text { Periurban } \\
\text { Education only }\end{array}$ & 54.5 & 44.9 & 36.4 & 15.4 & 16 & 14.3 & 22.7 & 30.8 \\
\hline $\begin{array}{l}\text { Periurban } \\
\text { Control }\end{array}$ & 48.6 & -- & 51.4 & -- & 8.6 & & 48.6 & -- \\
\hline
\end{tabular}

